\title{
Nota sobre la cirrosis hepática parasitológica en ganado porcino.
}

\author{
María Pía Meledandri \\ Municiplaidad de Traiguén/Pragrama PDTI INDAP, Unidad Operativa Comunal, \\ Territorio 1. Email: pia_mele@hotmail.com
}

Recibido: 23 de mayo de 2017; Aceptado: 06 de junio de 2017.

La cirrosis hepática es una patología que cursa con proliferación de tejido intersticial de aspecto cicatricial. La superficie del órgano se torna rosado-amarillento, de aspecto marmóreo, con relieves y puede presentar nódulos de coloración amarillo opaco (López y Rivas 2012). Chamizo (1995) hace distinción varios tipos de cirrosis hepática:

La cirrosis hepática tóxica de forma atrófica o cirrosis portal, también llamada de Laennee, macroscópicamente cursa con disminución del tamaño del órgano, de consistencia firme y con presencia de nodulaciones en la superficie del parénquima. Microscópicamente presenta pseudolobulaciones producto de la proliferación de tejido inter e intralobulillar

La cirrosis hepática tóxica de forma hipertrófica o cirrosis intralobulillar, también llamada de Hanot, es una proliferación de tejido fibroso dentro de los lobulillos, que rodea los hepatocitos (cirrosis pericelular). Macroscópicamente se observa aumento de tamaño del hígado, firme y duro a la palpación. En tanto, microscópicamente los cordones hepáticos y hepatocitos están atrofiados a causa de la proliferación del tejido conectivo. La cirrosis cardiaca es un proceso crónico progresivo y difuso de proliferación de tejido conectivo fibroso.

Las larvas de Stephanurus dentatus y Ascaris suum producen en el cerdo cirrosis parasitaria hematógena, producto de su migración al hígado a través de la vena porta, desde donde acceden al parénquima, y en la cápsula forman tractos necróticos que provocarán la proliferación de tejido conectivo cicatricial hasta extenderse por el intersticio. Macroscópicamente a la palpación el órgano es firme, posee áreas de tonos rojizos que posteriormente se convertirán en blanco a blancoamarillento y al corte se aprecia tejido necrótico y cicatricial. Microscópicamente se observan áreas de tejido necrótico y abundantes eosinófilos en el tejido neoformado. 
La cirrosis parasitaria biliar es producida por la ingesta de trematodos como fasciola hepática. Los huevos eclosionan en el duodeno desde donde emigran atravesando el intestino hasta la cápsula hepática y alcanzan los conductos biliares donde madurarán en 2 a 3 meses.

La cirrosis congénita sólo ha sido estudiada en crías muertas al parto en bovinos. Se cree que las causas podrían ser infecciosas, mediante la trasmisión intraplacentaria de aflatoxinas como posible etiología. Macroscópicamente el órgano se encuentra de tamaño normal de coloración pardo claro a ocre, firme, de aspecto granulado o con nodulaciones que confieren cierto relieve a la cara parietal del órgano. Microscópicamente se puede observar proliferación de tejido conectivo y proliferación de los conductos biliares.

"Las micotoxinas son producidas y eliminadas por hongos que crecen en granos como maíz, trigo, sorgo y otros" (Trujano et al 2010). Las principales micotoxinas que cursan con afecciones hepáticas son las aflatoxinas y fumonisinas. Las aflatoxinas afectan en mayor medida a la especie porcina entre la semana 1 y 4 de edad (mayor susceptibilidad), siendo el hígado el órgano más afectado (López y Rivas 2012), son producidas por Aspergilus flavus y A. parasiticus. Por su parte, las fumonisinas pueden producir cirrosis hepática y edema pulmonar en cerdos. Se han descrito hasta 3 tipos (FB1, FB2 y FB3) producidos por Fusarium moniliforme y F. proliferatum (Gallego 2010).

En un estudio realizado en porcinos con hepatosis dietética que presentaban úlceras gástricas, Garcia-Mochales y Llanes (2011) basándose en las propiedades antioxidantes naturales de la Vitamina $E$, como poderoso protector de membrana y tratamiento de elección en cirrosis hepática, administraron Vitamina E y Se inyectable a los lechones afectados obteniendo resultados favorables de hasta un $85 \%$.

Muy por el contrario, Villanueva (2011) señala que en altas concentraciones el Se resulta tóxico, manejando un margen tolerable de 2 ppm y nivel tóxico de 8 ppm $(\mathrm{ppm}=$ partes por millón $=$ miligramos por kilo de alimento $=$ gramos por tonelada $)$. Es más, síntomas de intoxicaciones como anemia, rigidez, parálisis, adelgazamiento, atrofia y cirrosis hepática en animales jóvenes preferentemente son provocados por plantas que acumulan Se que absorben de suelos ricos en este mineral, como el trigo (Taylor 1989).

\section{REFERENCIAS}


Chamizo, EG 1995, Patología especial y diagnóstico de las enfermedades de los animales domésticos, Universidad Autónoma de Baja California, México.

Gallego, LM 2010, Micotoxinas [Página web], Analiza Calidad Centro Europeo de Empresas e Innovación, consultado: 13 junio de 2013, http://www.analizacalidad.com/docftp/fi1136microtoxinas.pdf

Garcia-Mochales, CA y Llanes, N 2011, Úlceras gástricas agudas en porcino, Portal Veterinaria Albéitar [Página web], consultado: 28 junio de 2013, http://albeitar.portalveterinaria.com/noticia/8248/ARTICULOS-PORCINOARCHIVO/ UI ceras-gastricas-agudas-en-porcino.html.

López, CL y Rivas, JIJ 2012, 'Prevalencia de las diferentes patologías causantes de decomiso de hígados de bovinos en la inspección post-mortem, sacrificados en el Matadero Municipal de San Salvador', licenciadas en medicina veterinaria y zootecnia, Universidad de El Salvador, Facultad de Ciencias Agronómicas, Departamento de Medicina Veterinaria, Ciudad Universitaria, El Salvador.

Taylor, DJ 1992, Enfermedades del cerdo, $2^{\circ}$ ed., Editorial El Manual Moderno, México.

Trujano, M; Marquez, N; Sierra, J y Solorio, S 2010, Problemas de salud observados en cerdos y su relación con micotoxinas [Página web], Lesaffre Feed Additives, México, consultado: 13 junio de 2013, http://www.engormix.com/MAporcicultura/sanidad/articulos/problemas-salud-observados-cerdost3075/p0.htm.

Villanueva, G] 2011, nutrición del ganado: selenio [Página web], consultado: 24 junio de 2013, http://www.produccion-animal.com.ar/suplementacion_mineral/147selenio.pdf. 